\title{
Diastereomer Assignment of an Olefin-Linked bis-Paracyclophane by Ion Mobility Mass Spectrometry
}

\author{
Erin Shammel Baker, ${ }^{\mathrm{a}}$ Janice W. Hong, ${ }^{\mathrm{a}}$ Jennifer Gidden, ${ }^{\mathrm{a}}$ Glenn P. Bartholomew, ${ }^{\mathrm{a}}$ \\ Guillermo C. Bazan, ${ }^{\mathrm{a}, \mathrm{b} *}$ and Michael T. Bowers ${ }^{\mathrm{a} *}$ \\ Department of Chemistry ${ }^{\mathrm{a}}$, Department of Materials ${ }^{\mathrm{b}}$, Center for Polymers and Organic \\ Solids, University of California, Santa Barbara, CA 93106
}

Supplementary Information

General Details. All reactions were conducted using oven dried glassware under an argon or nitrogen atmosphere and were stirred magnetically. ${ }^{1} \mathrm{H}$ and ${ }^{13} \mathrm{C}$ NMR spectra were recorded on a Varian Inova $400 \mathrm{MHz}$ NMR and Varian Unity $500 \mathrm{MHz}$ NMR spectrometers. Mass spectrometry was performed by the UC Santa Barbara Mass Spectrometry Lab. Reagents were obtained from Aldrich Co. and used as received.

rac-(E)-1,2-bis-[4,4-[2.2]-paracyclophanyl]ethene (rac-1). In a glove box, a $50 \mathrm{~mL}$ round bottom was charged with $500 \mathrm{mg}(2.1 \mathrm{mmol})$ of rac-4-vinyl[2.2]paracyclophane, $17 \mathrm{mg}(1 \mathrm{~mol} \%)$ of (tricyclohexylphosphine)(1,3)-dimesityl-4,5-dihydroimidazol-2ylidene)methylidene ruthenium dichloride, a Teflon stirbar and c.a. $20 \mathrm{~mL} \mathrm{of} \mathrm{CH}_{2} \mathrm{Cl}_{2}$. This mixture was allowed to stir for 30 minutes in the inert glovebox atmosphere. A needle valve was affixed to the round bottom flask and the reaction was transferred to a Schlenk line and heated to $45^{\circ} \mathrm{C}$ overnight. The reaction mixture was diluted with additional $\mathrm{CH}_{2} \mathrm{Cl}_{2}$ and washed three times with deionized water. The organic layer was dried over $\mathrm{MgSO}_{4}$, filtered and the solvent removed under vacuum. The resulting solid was spun onto chromatographic silica and separated on a $90 \mathrm{~g}$ silica column with $30 \%$ 
$\mathrm{CH}_{2} \mathrm{Cl}_{2}$ in hexanes used as eluant, yielding $208 \mathrm{mg}(45 \%)$ of the title compound. ${ }^{1} \mathrm{H}$ $\operatorname{NMR}\left(\mathrm{CDCl}_{3}\right): 6.963(\mathrm{~s}, 1 \mathrm{H}) ; 6.706(\mathrm{~s}, 1 \mathrm{H}) ; 6.681(\mathrm{dd}, J=8.0,1.6 \mathrm{~Hz}, 1 \mathrm{H}) ; 6.590-6.505$ $(\mathrm{m}, 4 \mathrm{H}) ; 6.430(\mathrm{dd}, J=8.0,1.6 \mathrm{~Hz}, 1 \mathrm{H}) .{ }^{13} \mathrm{C} \mathrm{NMR}\left(\mathrm{CD}_{2} \mathrm{Cl}_{2}\right): 140.631,140.002,139.903$, $138.909,138.568,135.488,133.583,133.538,132.218,132.180,130.867,130.359$, 127.992, 35.898, 35.663, 35.352, 34.480. HREI: 440.2511, •= 1.6 ppm.

meso-(E)-1,2-bis-[4,4-[2.2]-paracyclophanyl]ethene (meso-1). In a glove box, a $10 \mathrm{~mL}$ round bottom was charged with $67 \quad \mathrm{mg} \quad(0.233 \mathrm{mmol})$ of rac-4bromo[2.2]paracyclophane, $56 \mathrm{mg}(0.239 \mathrm{mmol}) \mathrm{rac}$-4-vinyl[2.2]paracyclophane, $60 \mathrm{mg}$ (0.197 mmol) tri(o-tolyl)phosphine, $2 \mathrm{mg}(0.009 \mathrm{mmol})$ palladium acetate, and a Teflon stir bar, and was then equipped with a reflux condenser and needle valve. The reaction flask was taken out of the box and transferred to a Schlenck line, where 3mL DMF and $0.5 \mathrm{~mL}$ triethylamine were added via syringe. The slurry was degassed by three freezepump-thaw cycles, then heated to $70^{\circ} \mathrm{C}$ under an argon atmosphere. Upon reaching temperature, all starting material dissolved to form a pink solution. The reaction was monitored by TLC, and was stopped after 36 hours. The reaction mixture was diluted with $\mathrm{CH}_{2} \mathrm{Cl}_{2}$ and washed three times with deionized water. The organic layer was dried over $\mathrm{MgSO}_{4}$, filtered, and the solvent removed under vacuum. The major product was enriched by column chromatography (eluant $20 \% \quad \mathrm{CH}_{2} \mathrm{Cl}_{2}$ in hexanes). Both diastereomers can be isolated in small amounts. ${ }^{1} \mathrm{H}$ NMR $\left(\mathrm{CDCl}_{3}\right): 6.956(\mathrm{~s}, 1 \mathrm{H}) ; 6.911$ $(\mathrm{dd}, J=7.75,2.0 \mathrm{~Hz}, 1 \mathrm{H}) ; 6.701(\mathrm{~d}, J=1.5 \mathrm{~Hz}, 1 \mathrm{H}) ; 6.618(\mathrm{dd}, J=8,1.5 \mathrm{~Hz}) ; 6.586-$ $6.552(\mathrm{~m}, 2 \mathrm{H}) ; 6.541-6.500(\mathrm{~m}, 2 \mathrm{H}) ; 3.678-3.627(\mathrm{~m}, 1 \mathrm{H}) ; 3.273-3.050(\mathrm{~m}, 6 \mathrm{H})$; 2.955-2.893 (m, $1 \mathrm{H})$. Sample was too insoluble to obtain a ${ }^{13} \mathrm{C}$ NMR. HREI: 440.2519, • $=3.4$ ppm. 
$(E)$-1,2-bis-[4,4-[2.2]-paracyclophanyl]oxirane $((R, S, S, S)-2,(R, R, R, S)-2,(R, S, S, R)-2$, $(\boldsymbol{S}, \boldsymbol{R}, \boldsymbol{R}, \boldsymbol{S})-\mathbf{2},(\boldsymbol{R}, \boldsymbol{R}, \boldsymbol{R}, \boldsymbol{R})-\mathbf{2},(\boldsymbol{S}, \boldsymbol{S}, \boldsymbol{S}, \boldsymbol{S})-\mathbf{2})$. A $5 \mathrm{~mm}$ NMR tube was charged with $1.2 \mathrm{mg}$ (3 $\mu \mathrm{mol})$ of meso-1 or rac-1, $0.8 \mathrm{mg}(5 \mu \mathrm{mol})$ meta-chloroperoxybenzoic acid (MCPBA), and $2 \mathrm{~mL} \mathrm{CD}_{2} \mathrm{Cl}_{2}$. The reaction was allowed to proceed overnight. NMR revealed disappearance of the peroxy acid proton peak. HREI: $456.2470, \bullet=3.7 \mathrm{ppm}(R, S, S, S)-\mathbf{2}$, $(R, R, R, S)-\mathbf{2}$; HREI: 456.24496, $\quad=0.8 \mathrm{ppm}(R, S, S, R)-\mathbf{2}, \quad(S, R, R, S)-\mathbf{2}, \quad(R, R, R, R)-\mathbf{2}$, $(S, S, S, S)-\mathbf{2}$.

Neutral Olefin-Linked Theoretical Calculations. Theoretical calculations were conducted on neutral olefin-linked $\mathrm{pCp}$ molecules. The lowest-energy structures for $\mathrm{rac}$ $\mathbf{1}$ and meso-1 are shown below. In the lowest energy family of structures rac-1 is in an up/up conformation, while meso-1 adopts an up/down conformation. Since these are the same configurations as the lowest-energy structures for $\mathrm{Na}^{+} \mathrm{rac}-\mathbf{1}$ and $\mathrm{Na}^{+} m e s o-\mathbf{1}$, it can be seen that sodium acts as a spectator ion and does not force a particular conformation.
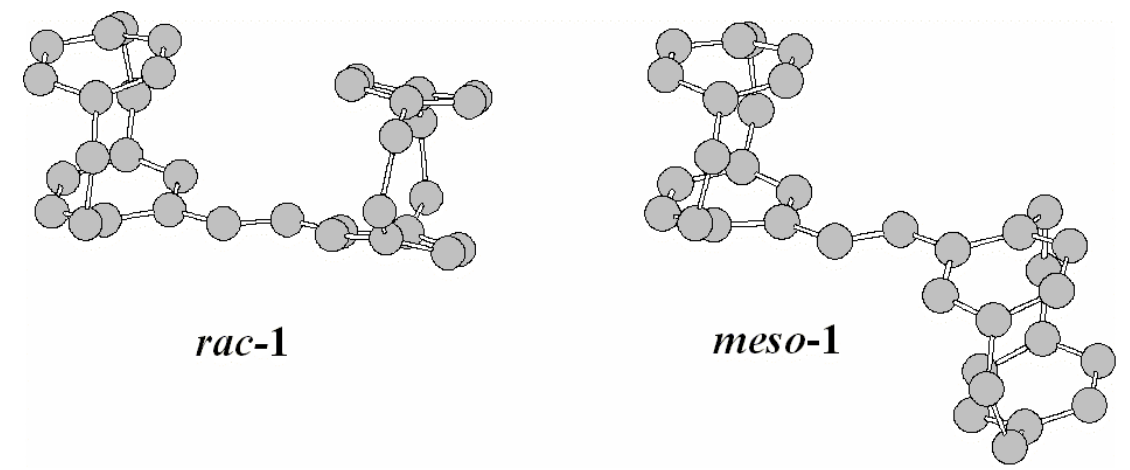

DFT Energy Calculations. DFT calculations were carried out using the B3LYP hybrid functional ${ }^{1,2}$ and the standard $6-31 \mathrm{G}$ basis set. These calculations were performed using 
the Gaussian 98 package ${ }^{3}$. Geometry optimizations of low-energy structures obtained from molecular mechanics/dynamics for both the rac-1 and meso-1 conformers were performed in order to determine if either conformer would be energetically favored by the synthesis. The calculations indicate that the rac and meso forms are energetically degenerate.

Rotation Barrier Calculations. The rotation barrier for rac-1 being in an up/up position versus an up/down position or meso-1 being in an up/up position instead of an up/down position was investigated using DFT calculations at the B3LYP/6-31G level. In these calculations, the up/up position for rac-1 was $15 \mathrm{kcal} / \mathrm{mol}$ lower in energy than the up/down position and the barrier of rotation between these two forms was $20 \mathrm{kcal} / \mathrm{mol}$. Meso-1 followed the same trend as its up/down position was $15 \mathrm{kcal} / \mathrm{mol}$ lower in energy than the up/up position and the barrier of rotation between these two forms was also 20 $\mathrm{kcal} / \mathrm{mol}$.

\section{References}

1. P.J. Stevens, F.J. Devlin, C.F. Chablowski and M.J. Frisch. J. Phys. Chem. 98 (1994), p. 11623.

2. a) A.K. Becke. J. Chem. Phys. 98 (1993), p. 5648 . b) A.D. Becke. Phys. Rev. A 38 (1988), p. 3098.

3. M.J. Frisch, G.W. Trucks, H.B. Schlegel, G.E. Scuseria, M.A. Robb, J.R. Cheeseman, V.G. Zakrzewski, J.A. Montgomery Jr., R.E. Stratmann, J.C. Burant, S. Dapprich, J.M. Millam, A.D. Daniels, K.N. Kudin, M.C. Strain, O. Farkas, J. Tomasi, V. Barone, M. Cossi, R. Cammi, B. Mennucci, C. Pomelli, C. Adamo, S. Clifford, J. Ochterski, G.A. Petersson, P.Y. Ayala, Q. Cui, K. Morokuma, D.K. Malick, A.D. Rabuck, K. Raghavachari, J.B. Foresman, J. Cioslowski, J.V. Ortiz, A.G. Baboul, B.B. Stefanov, G. Liu, A. Liashenko, P. Piskorz, I. Komaromi, R. Gomperts, R.L. Martin, D.J. Fox, T. Keith, M.A. Al-Laham, C.Y. Peng, A. Nanayakkara, C. Gonzalez, M. Challacombe, 
P.M.W. Gill, B. Johnson, W. Chen, M.W. Wong, J.L. Andres, C. Gonzalez, M. HeadGordon, E.S. Replogle, J.A. Pople, Gaussian, Inc., Pittsburgh, PA, 1998. 